\title{
Treatment outcomes of various types of tuberculosis in Pakistan, 2006 and 2007
}

\author{
A.A. Chughtai, ${ }^{1}$ C.R. MacIntyre, ${ }^{2}$ Y.A. Wang, ${ }^{3}$ Z. Gao ${ }^{2}$ and W. Khan ${ }^{4}$
}

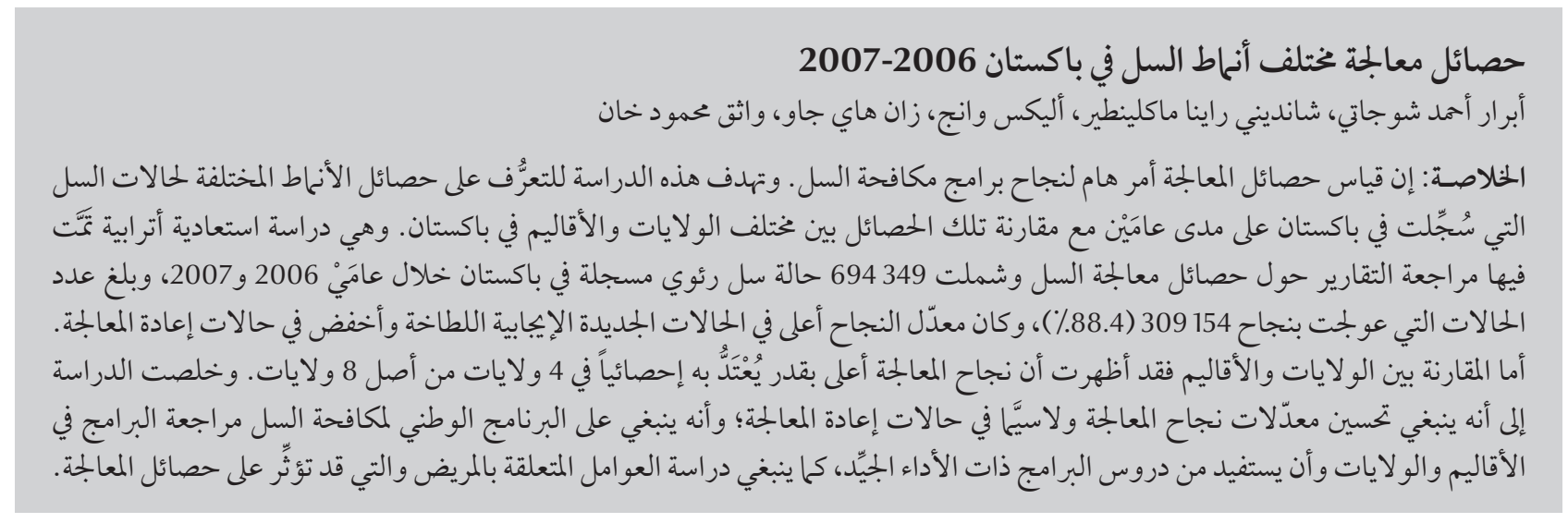

ABSTRACT Measuring treatment outcome is important for successful tuberculosis (TB) control programmes. The purpose of this study was to examine the outcomes of various types of TB cases registered in Pakistan over a 2-year period and compare those outcomes among the different provinces and regions of the country. A retrospective, cohort study was conducted in which TB treatment outcome reports were reviewed. Of the 349694 pulmonary TB cases registered in Pakistan during 2006 and 2007, 309154 (88.4\%) were treated successfully. Treatment success was significantly higher in new smear-positive cases and lower in retreatment cases. Among the provinces and regions, treatment success was significantly higher in 4 out of 8 provinces. Treatment success needs to be improved, particularly in retreatment cases. The national TB control programme should review the provincial and regional programmes and learn lessons from well-performing programmes. Patient factors that may affect the treatment outcome should be also studied.

Résultats thérapeutiques pour les différents types de tuberculose au Pakistan en 2006 et 2007

RÉSUMÉ Mesurer les résultats thérapeutiques est important pour la réussite des programmes de lutte antituberculeuse. L'objectif de la présente étude était d'évaluer les résultats thérapeutiques des différents types de cas de tuberculose enregistrés au Pakistan au cours d'une période de deux ans et de comparer ces résultats avec ceux des différentes provinces et régions du pays. Une étude de cohorte rétrospective a été menée au cours de laquelle les rapports sur les résultats de traitement de la tuberculose ont été examinés. Sur les 349694 cas de tuberculose pulmonaire enregistrés au Pakistan en 2006 et 2007, 309154 (88,4 \%) ont été traités avec succès. Le taux de guérison était nettement supérieur pour les nouveaux cas à frottis positif et inférieur pour les cas de retraitement. En outre, au niveau des provinces et des régions, il était nettement plus élevé dans 4 des 8 provinces. Le taux de guérison doit être amélioré, notamment pour les cas de retraitement. Le programme national de lutte antituberculeuse devrait revoir les programmes dans les provinces et les régions et tirer les enseignements des programmes performants. Les facteurs concernant le patient qui pourraient affecter les résultats du traitement doivent aussi être étudiés.

${ }^{7}$ National Tuberculosis Control Programme, Islamabad, Pakistan (Correspondence to A.A. Chughtai: doctorahmad75@gmail.com). ${ }^{2}$ School of Public Health and Community Medicine; ${ }^{3}$ School of Women and Child Health, University of New South Wales, Sydney, Australia. ${ }^{4}$ World Health Organization Regional Office for the Eastern Mediterranean, Cairo, Egypt.

Received: 22/11/11; accepted: 22/04/12 


\section{Introduction}

Tuberculosis (TB) is one of the major public health problems in $\mathrm{Pa}$ kistan. The country ranks 6th among the high-burden TB countries and harbours $63 \%$ of the disease burden in the Eastern Mediterranean Region. The incidence of smear-positive TB cases is $97 / 100000$ and the incidence of all types of TB cases is $231 / 100000$ [1]. The Pakistan national TB control programme (NTP) adopted the World Health Organization (WHO) DOTS treatment strategy in 1995 [2]. After lapsing, the NTP was revived in 2001 and $\mathrm{TB}$ was declared a national emergency [3]. Since then efforts have been made to expand partnerships and bring all stakeholders on board in order to control this disease more effectively. In line with Millennium Development Goals the case detection rate for new smear-positive cases increased from $2.8 \%$ in 2000 to $75 \%$ in 2008 . The treatment success rate (TSR) has also increased from $74 \%$ in 2000 to $87 \%$ in 2007 and been maintained to date, against the target of $85 \%[4]$.

Measuring treatment outcome is always important for successful TB control programmes. Although many factors affect the successful outcome of TB treatment, the type of TB is the most important predictor of treatment outcome. The TSR is low in multi-drug resistant and other retreatment $\mathrm{TB}$ cases, including cases of relapse, treatment after failure and treatment after default. Studies also show that the chances of being cured reduces as sputum grading increases [5] and this is particularly significant in retreatment cases [6]. TSRs are considered good in DOTS areas [7]. Globally, TB is reported to be higher in males $[8,9]$, but treatment compliance is usually higher in females [10-14]. Treatment outcome has been also assessed on the basis of treatment periods [15-18] and among different regions [16]. In most of these studies, the TSR and cure rate increased over time $[17,18]$. In this national study in Pakistan the outcome of TB cases registered from 2006-07 was assessed on the basis of the time period, types of TB and different provinces/regions.

\section{Methods}

\section{Study design}

A retrospective cohort study was conducted to evaluate the factors associated with the outcome of $\mathrm{TB}$ cases registered in Pakistan. TB treatment outcome data of all provinces and regions was included in this study.

\section{Data collection}

TB case finding and treatment outcome reports were reviewed and all patients registered and reported during 2006 07 were included in the study. A total of $409366 \mathrm{~TB}$ cases were reported during this period, out of which 349694 were pulmonary and 59772 were extrapulmonary. As the NTP does not declare the outcome of extrapulmonary cases only pulmonary $\mathrm{TB}$ cases were included in this study.

The NTP uses the WHO's recommended recording and reporting system for TB surveillance. The WHO has developed a set of tools and these have been recently revised through a consultative process [19]. The NTP has adopted these revised recording and reporting tools, with some minor modifications, in the local context. The NTP has a set of nationally agreed nomenclature and definitions for various treatment outcomes of the TB patients. The definitions used in the programme are compatible with international recommendations. We used the standard treatment outcomes: cured, treatment complete, died, treatment failure, defaulted and transferred out.

The data were analysed by type of TB case (new smear-positive, new smear-negative, relapsed, treatment after failure and treatment after default), year (2006 and 2007) and region [Azad
Jammu and Kashmir Province (AJK), Balochistan, Federally Administered Tribal Areas (FATA); Northern Areas (NA), North-West Frontier Province (NWFP), Punjab, Sindh and the Federal TB control centre].

\section{Ethical issues}

Ethical clearance was obtained from the human research ethics advisory panel of University of New South Wales, Australia. Permission was sought from the NTP in the Ministry of Health, Pakistan, to use de-identified TB data for this study.

\section{Data entry and analysis}

The TB treatment outcome data of all districts was entered into SPSS, version 17. All data were double-checked for errors and missing values. Means and frequencies were used for the description of various variables. Logistic regression was used to estimate the odds ratios (OR) and their 95\% confidence intervals (CI), with the TB treatment result as an outcome. First, univariate analyses were performed to examine the effect of each variable on the different outcomes of TB. Then multivariate logistic models were constructed; in the Punjab province, new smear-positive TB cases and the year 2006 were reference categories. In all statistical tests, $P$-value $<0.05$ was considered significant.

\section{Results}

A total of 349694 pulmonary TB cases were included in the study: 153063 cases were registered in 2006 and 196631 cases in 2007. Among the total cases, most were new cases (153590 smear-positive and 183448 smearnegative); $<4 \%$ were retreatment cases (6839 relapsed, 1296 treatment after failure and 4521 treatment after default) (Table 1). A significant variation was seen in the type of $\mathrm{TB}$ cases registered in different provinces and regions. 


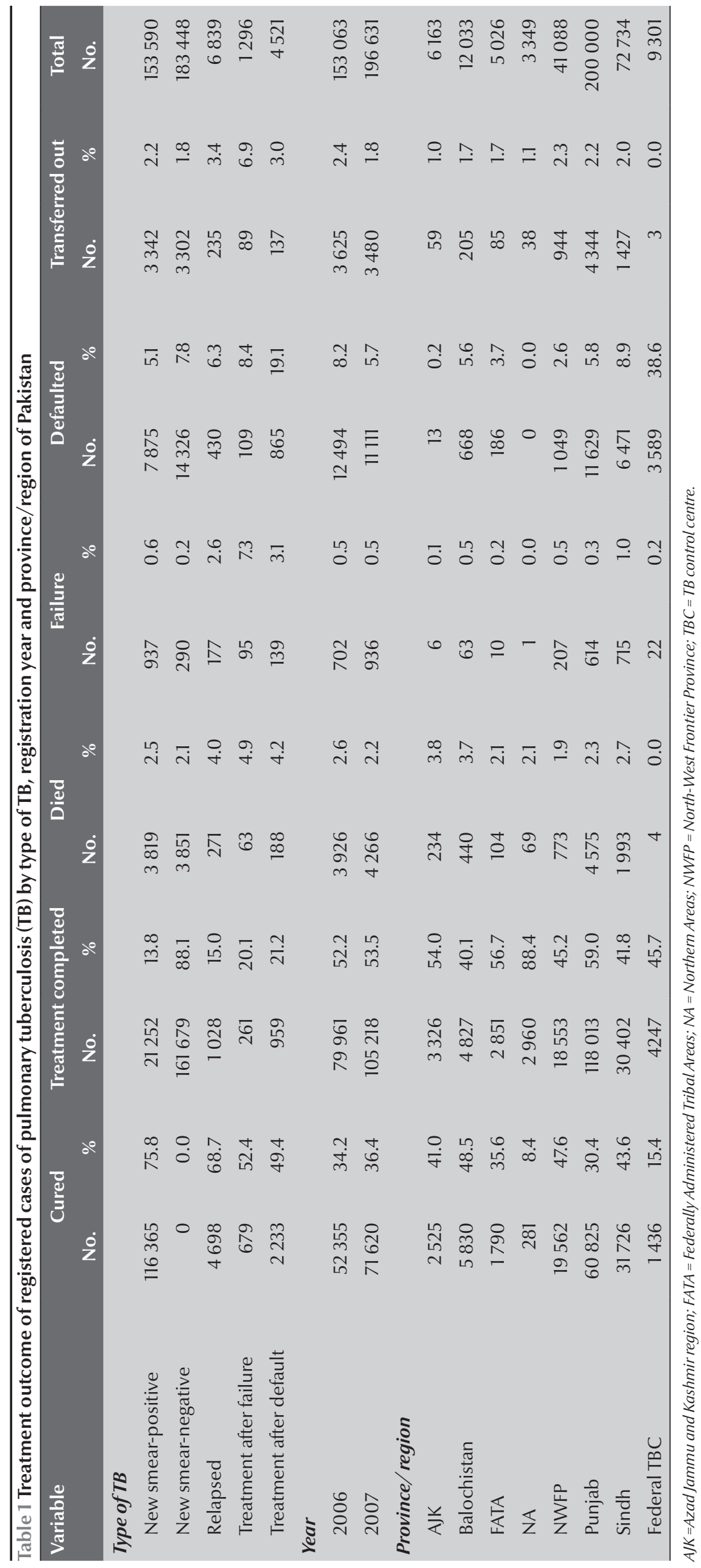

Of the total cases registered during 2006 and 2007123975 (40.1\%) cases were cured and 185179 (59.9\%) completed treatment. Thus 309154 $(88.4 \%)$ cases were classified as treatment successful (Table 1). Cure and treatment completion rates were high in new $\mathrm{TB}$ cases and low in retreatment cases (relapsed, treatment after failure and treatment after default). Death, failure and default rates were high in retreatment cases.

Univariate analysis showed a high TSR in smear-positive cases compared with all other types of TB (Table 2). New smear-negative cases were $14 \%$ less likely to be treated successfully than new smear-positive cases (OR 0.86, 95\% CI: 0.84-0.88). Among the retreatment cases, TSRs were lowest for the treatment after default cases (OR 0.28, 95\% CI: 0.26-0.30), followed by the treatment after failure (OR 0.30, 95\% CI: $0.27-0.34$ ) and relapsed cases (OR 0.60, 95\% CI: 0.56-0.63). TSR significantly improved in 2007 compared with 2006 (OR 1.34, 95 CI: 1.32-1.37). Compared with Punjab province, more cases were successfully treated in the NA (OR 3.55, 95\% CI: 2.90-4.30), AJK (OR 2.21, 95\% CI: 1.98-2.50), NWFP (OR 1.51, 95\% CI: $1.46-1.58$ ) and FATA (OR 1.42, 95\% CI: 1.28-1.58). In Baluchistan, Sindh and the Federal $\mathrm{TB}$ centre, the outcome was poor when compared with the Punjab (Table 2).

The death rate was significantly lower in new smear-negative cases (OR 0.84, 95\% CI: 0.80-0.88) and higher in relapsed (OR 1.62, 95\% CI: 1.43-1.83), treatment after failure (OR $2.00,95 \%$ CI: $1.55-2.59)$ and treatment after default cases (OR 1.7, 95\% CI: $1.46-1.98)$. The death rate was lower in 2007 compared with 2006 (OR 0.996, 95\% CI: 0.995-0.997). Compared with Punjab, more patients died in AJK (OR 1.69, 95\% CI: 1.47-1.93), Baluchistan (OR 1.62, 95\% CI: 1.47-1.92) and Sindh (OR 1.20, 95\% CI: 1.14-1.27) provinces. 


\begin{tabular}{|c|c|c|c|c|c|c|c|c|}
\hline \multirow[t]{3}{*}{ Variable } & \multicolumn{4}{|c|}{ Treatment success } & \multicolumn{2}{|c|}{ Univariate analysis } & \multicolumn{2}{|c|}{ Multivariate analysis ${ }^{\mathrm{b}}$} \\
\hline & \multicolumn{2}{|c|}{ Yes } & \multicolumn{2}{|c|}{ No } & \multirow[b]{2}{*}{ OR } & \multirow[b]{2}{*}{$95 \% \mathrm{Cl}$} & \multirow[b]{2}{*}{ OR } & \multirow[b]{2}{*}{$95 \% \mathrm{Cl}$} \\
\hline & No. & $\%$ & No. & $\%$ & & & & \\
\hline \multicolumn{9}{|l|}{ Type of TB } \\
\hline New smear-positive ${ }^{a}$ & 137617 & 89.6 & 15973 & 10.4 & 1.00 & - & 1.00 & - \\
\hline New smear-negative & 161679 & 88.1 & 21769 & 11.9 & 0.86 & $0.84-0.88$ & 0.89 & $0.87-0.91$ \\
\hline Relapsed & 5726 & 83.7 & 1113 & 16.3 & 0.60 & $0.56-0.63$ & 0.56 & $0.53-0.60$ \\
\hline Treatment after failure & 940 & 72.5 & 356 & 27.5 & 0.30 & $0.27-0.34$ & 0.33 & $0.29-0.38$ \\
\hline Treatment after default & 3192 & 70.6 & 1329 & 29.4 & 0.28 & $0.26-0.30$ & 0.28 & $0.26-0.30$ \\
\hline \multicolumn{9}{|l|}{ Year } \\
\hline $2006^{\mathrm{a}}$ & 132316 & 86.4 & 20747 & 13.6 & 1.00 & - & 1.00 & - \\
\hline 2007 & 176838 & 89.9 & 19793 & 10.1 & 1.34 & $1.32-1.37$ & 1.35 & $1.32-1.38$ \\
\hline \multicolumn{9}{|l|}{ Province } \\
\hline AJK & 5851 & 94.9 & 312 & 5.1 & 2.21 & $1.98-2.50$ & 2.24 & $2.00-2.51$ \\
\hline Balochistan & 10657 & 88.6 & 1376 & 11.4 & 0.92 & $0.86-0.97$ & 0.89 & $0.84-0.95$ \\
\hline FATA & 4641 & 92.3 & 385 & 7.7 & 1.42 & $1.28-1.58$ & 1.46 & $1.31-1.62$ \\
\hline NA & 3241 & 96.8 & 108 & 3.2 & 3.55 & $2.93-4.30$ & 3.56 & 2.94-4.32 \\
\hline NWFP & 38115 & 92.8 & 2973 & 7.2 & 1.51 & $1.46-1.58$ & 1.52 & $1.46-1.58$ \\
\hline Punjab & 178838 & 89.4 & 21162 & 10.6 & 1.00 & - & 1.00 & - \\
\hline Sindh & 62128 & 85.4 & 10606 & 14.6 & 0.70 & $0.68-0.71$ & 0.71 & $0.70-0.73$ \\
\hline Federal TBC & 5683 & 61.1 & 3618 & 38.9 & 0.18 & $0.18-0.19$ & 0.19 & $0.18-0.20$ \\
\hline
\end{tabular}

${ }^{a}$ Reference category.

${ }^{b}$ In the multivariate analysis, all variables in the univariate analysis were considered.

AJK=Azad Jammu and Kashmir region; FATA = Federally Administered Tribal Areas; NA=Northern Areas; NWFP=North-West Frontier Province; TBC = TB control centre.

$O R=$ odds ratio $; C I=$ confidence interval.

After multivariate analysis with adjustment for the type of TB and the year of registration there were no major changes in the ORs.

\section{Discussion}

Declaring treatment outcomes is important for monitoring the quality of case management and the progress of TB control programmes. Data from 2006 and 2007 were analysed in this study. The treatment outcome was significantly higher in 2007 compared with 2006; TSRs increased and death rates decreased significantly in 2007. The TSR of new smear-positive cases was $74 \%$ in 2000 and this had increased to $91 \%$ by 2007 . Data from the NTP Pakistan showed that the TSR of retreatment cases was $66 \%$ in 2002 and had increased to $79 \%$ in 2007 [20].
It is also interesting to note that the NTP was in the DOTS expansion phase from 2002 to 2005 and achieved $100 \%$ DOTS coverage in 2005. With this rapid DOTS expansion, the TSR also increased in that time period [20]. Some other studies also showed that the DOTS population coverage had a significant effect on the overall TSR and countries with full DOTS coverage had an 18\% higher rate of successful treatment [21].

Treatment outcome is generally poor in retreatment TB cases [1], particularly in cases of treatment after failure [22]. Confirming WHO data [1], the outcome of retreatment cases in our study was poorer than smear-positive cases. Among the retreatment cases, we found that successful outcome was worse for the cases of treatment after default (OR 0.33, 95\% CI: 0.29-0.38) than treatment after failure (OR 0.28,
95\% CI: 0.26-0.30). TSRs were high in smear-positive cases and this was mainly due to the high default rate in other types of TB cases. New smear-positive cases are usually more severe than smear-negative cases, but less severe than retreatment cases. This may be a reason for the high number of deaths in retreatment cases compared with smear-positive cases. Among the retreatment cases, more cases of treatment after failure died (OR 1.88, 95\% CI: 1.45-2.42) than treatment after default (OR 1.68, 95\% CI: 1.44-1.95) and relapsed cases (OR 1.60, 95\% CI: 1.40-1.80). These results also highlight the possibility of drug resistance among treatment after failure cases who are sputum smearnegative at the start of treatment and become smear-positive during the course of treatment. Failure to treat in category 2 also resulted in treatment failure (this includes smear-positive relapses, failure, 


\begin{tabular}{|c|c|c|c|c|c|c|c|c|}
\hline \multirow[t]{3}{*}{ Variable } & \multicolumn{4}{|c|}{ Died } & \multicolumn{2}{|c|}{ Univariate analysis } & \multicolumn{2}{|c|}{ Multivariate analysis } \\
\hline & \multicolumn{2}{|c|}{ Yes } & \multicolumn{2}{|c|}{ No } & \multirow[b]{2}{*}{ OR } & \multirow[b]{2}{*}{$95 \% \mathrm{Cl}$} & \multirow[b]{2}{*}{ OR } & \multirow[b]{2}{*}{$95 \% \mathrm{Cl}$} \\
\hline & No. & $\%$ & No. & $\%$ & & & & \\
\hline \multicolumn{9}{|l|}{ Type of TB } \\
\hline New smear-positive ${ }^{a}$ & 3819 & 2.5 & 149771 & 97.5 & 1.00 & - & 1.00 & - \\
\hline New smear-negative & 3851 & 2.1 & 179597 & 97.9 & 0.84 & $0.80-0.88$ & 0.87 & $0.83-0.91$ \\
\hline Relapsed & 271 & 4.0 & 6568 & 96.0 & 1.62 & $1.43-1.83$ & 1.59 & $1.40-1.81$ \\
\hline Treatment after failure & 63 & 4.9 & 1233 & 95.1 & 2.00 & $1.55-2.59$ & 1.88 & $1.45-2.42$ \\
\hline Treatment after default & 188 & 4.2 & 4333 & 95.8 & 1.70 & $1.46-1.98$ & 1.68 & $1.45-1.95$ \\
\hline \multicolumn{9}{|l|}{ Year } \\
\hline $2006^{\mathrm{a}}$ & 3926 & 3.0 & 149170 & 97.0 & 1.00 & - & 1.00 & - \\
\hline 2007 & 4266 & 2.0 & 192365 & 98.0 & 0.996 & 0.995-0.997 & 0.83 & $0.79-0.87$ \\
\hline \multicolumn{9}{|l|}{ Province } \\
\hline AJK & 234 & 3.8 & 5929 & 96.2 & 1.69 & $1.47-1.93$ & 1.65 & $1.45-1.89$ \\
\hline Balochistan & 440 & 3.7 & 11593 & 96.3 & 1.62 & $1.47-1.92$ & 1.57 & $1.42-1.74$ \\
\hline FATA & 104 & 2.1 & 4922 & 97.9 & 0.90 & $0.74-1.14$ & 0.88 & $0.72-1.07$ \\
\hline NA & 69 & 2.1 & 3280 & 97.9 & 0.90 & $0.76-0.88$ & 0.96 & $0.76-1.22$ \\
\hline NWFP & 773 & 1.9 & 40315 & 98.1 & 0.82 & $0.76-0.88$ & 0.78 & $0.73-0.85$ \\
\hline Punjab $^{a}$ & 4575 & 2.3 & 195425 & 97.7 & 1.00 & - & 1.00 & - \\
\hline Sindh & 1993 & 2.7 & 70741 & 97.3 & 1.20 & $1.14-1.27$ & 1.13 & $1.07-1.19$ \\
\hline Federal TBC & 4 & 0.0 & 9297 & 100.0 & 0.01 & $0.007-0.05$ & 0.02 & $0.007-0.05$ \\
\hline
\end{tabular}

${ }^{a}$ Reference category.

${ }^{b}$ In the multivariate analysis, all variables in the univariate analysis were considered.

AJK=Azad Jammu and Kashmir region; FATA = Federally Administered Tribal Areas; NA=Northern Areas; NWFP=North-West Frontier Province; TBC = TB control centre.

$O R=$ odds ratio; $C I=$ confidence interval.

treatment after default and other smearpositive patients who have received anti-TB treatment for more than 1 month without being registered). Consequently, it would appear that there are more chances of drug resistance in these cases. These cases must be offered drug susceptibility testing and 2nd-line $\mathrm{TB}$ drugs from the beginning of treatment. The Pakistan NTP is using an 8-month regimen and 2 drugs, isoniazid and ethambutol, in the continuous phase of category 1 cases (this includes new cases of pulmonary $\mathrm{TB}$, whether smear-positive or -negative, extrapulmonary $\mathrm{TB}$ and other smear-negative and extrapulmonary patients). Studies have shown that a 6-month regimen, which contains rifampicin, has a good outcome and low relapse rate. Treatment failure and relapse is more common with an 8-month regimen [23]. Most high-burden TB countries have already shifted to the 6-month regimen containing rifampicin. It is therefore important to evaluate the efficacy of the 8-month regimen that does not contain rifampicin in Pakistan and, importantly, consider the 6-month regimen, which is more effective.

As a whole, the TSR was good in most of the regions except Sindh province and the Federal TB centre. Compared with Punjab, more cases were successfully treated in NA, AJK, NWFP and FATA. In Baluchistan, Sindh and the Federal TB centre, the outcome was poor compared with Punjab. The main reason for the low success rate seemed to be the high number of default cases. The population of the provinces, socioeconomic status and security situations are important factors to consider, as these can affect the default rate. At around 80 million people Punjab is the most populous province and contains half of the population of the Pakistan. The default rate was low in NA, AJK and FATA, presumably because the population is very low compared with Punjab. The population of NA is around 1 million and of FATA and AJK around 3 million. Furthermore, a poor law and order situation and low socioeconomic status may be a cause of high default rates. Both factors exist in Baluchistan, where the law and order situation is very poor and socioeconomic status is also low. The high default rate in Sindh is not easy to explain and the NTP should explore the reasons for this phenomenon. The Federal TB centre is a specialized $\mathrm{TB}$ institution, affiliated with the Federal government, and caters for cases not only from the Federal capital but also from neighbouring districts. As the Federal capital is not included in any province and region, the data were collected separately. The TSR was low 
and this may be due to poor case retention and a high default rate. Patients often come to the centre from remote areas and once they start improving they do not return. Interestingly, AJK had a good TSR but had a significantly higher number of deaths than other provinces. Although deaths were also lower in FATA and NA, this was not significant. Unfortunately, the causes of death cannot be assessed through the outcome data, as individual TB patients' data are required for this purpose.

According to our knowledge, this was the first study in Pakistan to evaluate the outcome of TB on the basis of types and regions. Nevertheless it also had some unavoidable limitations. Firstly, we were restricted to using TB patients' outcome reports. As individual patient data was not used in this study, many other variables which may also affect the treatment outcome-for example age, sex, sputum status and duration of symptoms - could not be accessed. Secondly, there was the possibility of misclassification, for example, patients were categorized as new or retreatment cases on their history of previous treatment. If patients are not categorized properly, there is a greater chance of unfavourable outcomes. Thirdly, the causes of deaths and default were not given in outcome reports and death and default are the main reasons for low treatment success. It is particularly important to know whether patients died due to TB or to other reasons. Fourthly, drug susceptibility and HIV status was not routinely tested before the start of treatment and this may have affected the outcome of TB. Finally, these data were mainly obtained from the public sector, as very few private providers sent data to the NTP. The NTP has recently started many public-private partnership ventures to involve the private sector in DOTS.

\section{Conclusion}

We found that the treatment outcome was generally high for new TB cases (smear-positive and smear-negative) and low for retreatment cases (relapsed, treatment after failure and treatment after default). Ways to improve TB case management need to be investigated to reduce the chances of recurrence and treatment failure, particularly in retreatment cases, perhaps by adopting the 6-month short-course regimen. The treatment outcome also varied among different provinces and regions. The NTP should review the provincial/ regional programmes and learn lessons from well-performing programmes. Defaulting from treatment was linked to poor outcomes in some areas. Causes of the high death rate in AJK and Baluchistan need to be explored and contributing factors addressed promptly. It is also essential to conduct further studies to assess the effect of other patient variables on the outcome of TB treatment.

\section{Acknowledgements}

I am thankful to the NTP Pakistan, for providing data for this project and giving permission to use that data for research purposes. Particularly I would like to acknowledge the support of Dr Noor Ahmad Baloch (national manager, NTP) and Dr Ejaz Qadeer (research coordinator, NTP).

\section{Funding: None.}

Competing interests: None declared.

\section{References}

1. Global tuberculosis report. Geneva, World Health Organization, 2010.

2. Strategic plan. Islamabad, National Tuberculosis Control Programme, Government of Pakistan, 2010.

3. Performance indicators. Pakistan National Tuberculosis Control Programme [online] (http://ntpgovpk/Performancelndicatorshtm, accessed 15 March 2013).

4. Revised national tuberculosis treatment guideline. Islamabad, National Tuberculosis Control Programme, Government of Pakistan, 2012.

5. Gopi P et al. Association of conversion and cure with initial smear grading among new smear positive pulmonary tuberculosis patients treated with category I regimen. Indian Journal of Medical Research, 2006, 123:807-814.

6. Mukherjee A et al. Outcomes of different subgroups of smearpositive retreatment patients under RNTCP in rural West Bengal, India. Rural and Remote Health, 2009, 9:926.

7. Dye C, Hosseini M, Watt C. Did we reach the 2005 targets for tuberculosis control? Bulletin of the World Health Organization, 2007, 85:364-369.

8. Ottamani S, Uplekar M. Gender and TB: points from routine records and reports. International Journal of Tuberculosis and Lung Disease, 2008, 12:827-828.
9. Weiss M. Gender and TB: socio-cultural aspects. International Journal of Tuberculosis and Lung Disease, 2008, 12:825-866.

10. Uplekar M et al. Attention to gender issues in tuberculosis control. International Journal of Tuberculosis and Lung Disease, 2001, 5:220-224.

11. Zellweger J, Coulon P. Outcome of patients treated for tuberculosis in Vaud county, Switzerland. International Journal of Tuberculosis and Lung Disease, 1998, 2:372-377.

12. Ditah IC et al. Monitoring tuberculosis treatment outcome: analysis of national surveillance data from a clinical perspective. Thorax, 2008, 63:440-444.

13. Lagrada L, Uehara N, Kawahara K. Analysis of factors of treatment completion in dots health facilities in metro Manila, Philippines: a case-control study. Kekkaku, 2008, 83:765-772.

14. Okanurak K, Kitayaporn D, Akarasewi P. Factors contributing to treatment success among tuberculosis patients: a prospective cohort study in Bangkok. International Journal of Tuberculosis and Lung Disease, 2008, 12:1160-1165.

15. Farah MG et al. Treatment outcome of new culture positive pulmonary tuberculosis in Norway. BMC Public Health, 2005, 5:14. 
16. Faustini A, Hall A, Perucci C. Tuberculosis treatment outcomes in Europe: a systematic review. European Respiratory Journal, 2005, 26:503-510.

17. Bao Q-S, Du Y-H, Lu C-Y. Treatment outcome of new pulmonary tuberculosis in Guangzhou, China 1993-2002: a registerbased cohort study. BMC Public Health, 2007, 7:344.

18. Hsu C-B et al. Preliminary evaluation of Taiwan's tuberculosis DOTS strategy. Taiwan Epidemiology Bulletin, 2008, 24:230-253.

19. Revised TB recording and reporting forms and registers - version 2006. Geneva, World Health Organization, 2006 (WHO/ $\mathrm{HTM} / \mathrm{TB} / 2006)$
20. National Tuberculosis Control Program. Government of Pakistan [online database] (http://ntp.gov.pk, accessed 30 March 2013).

21. Obermeyer Z, Abbott-Klafter J, Murray C. Has the DOTS strategy improved case finding or treatment success? An empirical assessment. PLoS One, 2008, 3(3):e1721.

22. Mehra $\mathrm{R}$ et al. Study of relapse and failure cases of CAT I retreated with CAT II under RNTCP-an eleven year follow up. Indian Journal of Tuberculosis, 2008, 55:188-191.

23. Treatment of tuberculosis: guidelines for national programs. Geneva, World Health Organization, 2003.

\section{Global tuberculosis report 2012}

Global tuberculosis report 2012 is the seventeenth global report on tuberculosis (TB) published by the World Health Organization (WHO) in a series that started in 1997. It provides a comprehensive and up-to-date assessment of the TB epidemic and progress in implementing and financing TB prevention, care and control at global, regional and country levels using data reported by 198 countries that account for over $99 \%$ of the world's TB cases.

The introductory chapter provides general background on TB as well as an explanation of global targets for TB control, the WHO's Stop TB Strategy and the Stop TB Partnership's Global Plan to Stop TB 2011 2015. The remaining six chapters of the report cover the burden of disease caused by TB; case notifications and treatment outcomes; financing TB care and control; diagnostics and laboratory strengthening for TB; addressing the co-epidemics of TB and HIV; and research and development for new TB diagnostics, drugs and vaccines.

The four annexes of the report include a thorough explanation of methods used to estimate the burden of disease caused by $\mathrm{TB}$, one-page profiles for high TB-burden countries, and tables of data on key indicators for all countries organized by WHO region.

Further information about this and other WHO publications is available at: http:/ /apps.who.int/bookorders/anglais/ homel.jsp 